\title{
RECOMBINANT VACCINIA VIRUSES WHICH EXPRESS MHV-JHM PROTEINS: PROTECTIVE IMMUNE RESPONSE AND THE INFLUENCE OF VACCINATION ON CORONAVIRUS-INDUCED ENCEPHALOMYELITIS
}

\author{
Egbert Flory, Albert Stühler, Hanna Wege, Stuart Siddell, and Helmut Wege \\ Institute of Virology and Immunobiology \\ Versbacher Strasse 7, D-97078 Würzburg, Germany
}

\section{SUMMARY}

Vaccinia-virus (VV) recombinants encoding either the nucleocapsid $(\mathrm{N})$ or the spike (S) protein of MHV-JHM were constructed to study the role of the immune reponse against defined coronavirus antigens. For the S-protein, a fusogenic (Sfus+) or non fusogenic variant (Sfus-) of the gene was inserted into the VV genome. A strong protection against acute encephalomyelitis (AE) was mediated in Lewis rats which were immunized by VV-Sfus+ and challenged with an otherwise lethal dose of MHV-JHM before the induction of S-specific IgG antibodies. By contrast, a VV recombinant encoding a variant non fusogenic S-protein or the $\mathrm{N}$-protein was not capable confering protection. In addition, we demonstrated that MHV-JHM $\mathrm{S}$-specific IgG antibodies elicited before MHV-JHM challenge modulated the disease process, changing it from an acute disease to subacute demyelinating encephalomyelitis (SDE).

\section{INTRODUCTION}

Coronavirus infections are valuable models to study the pathogenesis of virus-induced central nervous system (CNS) diseases. Especially the murine coronavirus MHV-JHM induces different courses of encephalomyelitis in mice or rats and can establish chronic infections 1 . In Lewis rats, several forms of the disease have been described 2.The acute encephalomyelitis (AE) is a rapidly progressing disease which leads to death of the animal. The subacute demyelinating encephalomyelitis (SDE) is a paralytic disease characterized by selective loss of myelin and inflammations in the white matter of the CNS. SDE develops after an incubation time of several weeks and can run a relapsing course.

The host immune response plays a critical role both in protection from acute disease and in modulating the development of chronic disease associated with demyelination. MHVJHM infections induce both cellular (T- cell-mediated) and humoral (B-cell mediated) responses. The role of the different components of the immune system for the course of infection is not clear. For example, the passive transfer of MAb specific for the spike (S), or other structural proteins, has been reported to protect mice or rats from lethal infection 3,4 . In addition, protective neutralizing antibodies were induced by passive immunization of mice with purified S-protein or S-protein decapeptide 5,6. T-cell-mediated immunity is generally believed to be crucial for the control of most viral infections and published data demonstrate that cellular immunity is required for the control of MHV-JHM infection 7,8,9,10.

However, little is known about virus-protein specific immune responses in Lewis rats. This study demonstrates the protective and disease-modulating capacity of an host immune response specific for individual MHV-JHM structural proteins. 


\section{RESULTS}

\section{Cloning and Expression of MHV-JHM Genes in VV-Recombinants}

The coding sequences of the nucleocapsid and two spike protein genes of MHV-JHM were inserted into the TK gene of VV strain WR. Construction and selection of recombinants containing foreign genes at the TK locus followed previously published procedures and will be described in detail elsewere.11 The expression of the N, Sfust and Sfus- proteins was confirmed by indirect immunofluorescence using monoclonal antibodies (Fig.1). Extensive syncytia formation caused by the fusogenic activity of S-protein was seen in VV-Sfus+ infected DBT-cells.
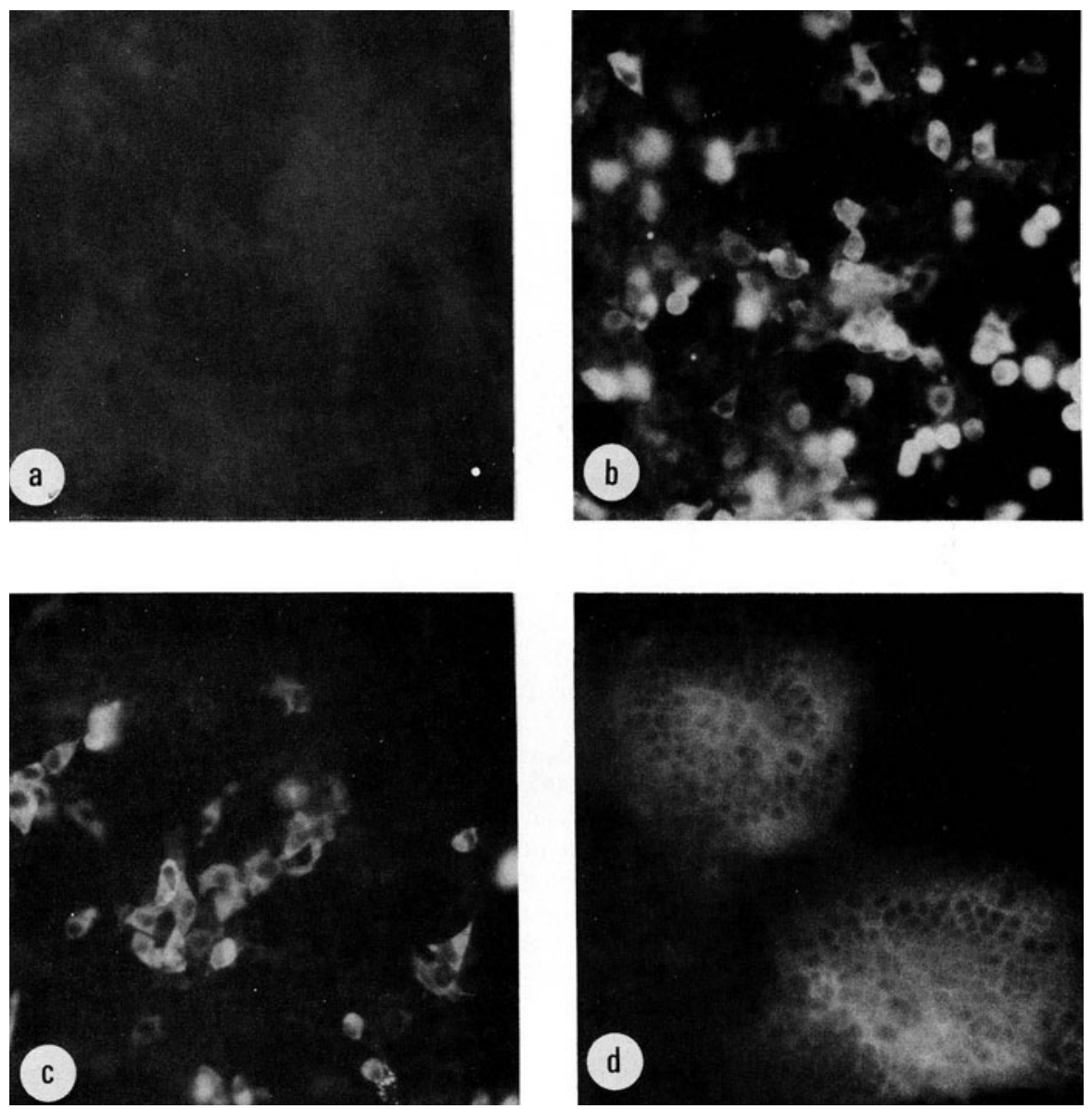

Figure 1. Immunofluorescence illustrating the expression of MHV-JHM proteins in DBT-cells infected with VV recombinants VV-N (b), VV-Sfus- (c) and VV-Sfus+ (d). The cells were incubated with the corresponding monoclonal anti-MHV-JHM antibodies followed by fluorescein isothiocyanate-conjugated anti-mouse immunoglobulin; (a) no staining of VV-wt infected cells with a mixture of anti-N and anti-S monoclonal antibodies (control); cytoplasmatic staining with anti-N monoclonal antibodies (b) and anti-S monoclonal antibodies (c); diffuse membrane staining with anti-S monoclonal antibodies with syncytia-formation (d). 


\section{Induction of Humoral Immune Responses Specific for MHV-JHM Proteins}

The immunogenic potential of the recombinant VV with regard to the MHV-JHM structural proteins was determined by immunization of adult Lewis rats. Serum samples were tested by ELISA for antiviral IgG and plaque reduction assays were used for monitoring virus neutralizing activity. The protein specificity was demonstrated by Westernblot analysis with purified MHV-JHM virus as antigen. The fusogenic VV-S recombinant induces a humoral immune response in a single shot immunization (Table 1). A high amount of S-specific

Table 1. Humoral immune response in Lewis rats induced by immunization with recombinant VV's

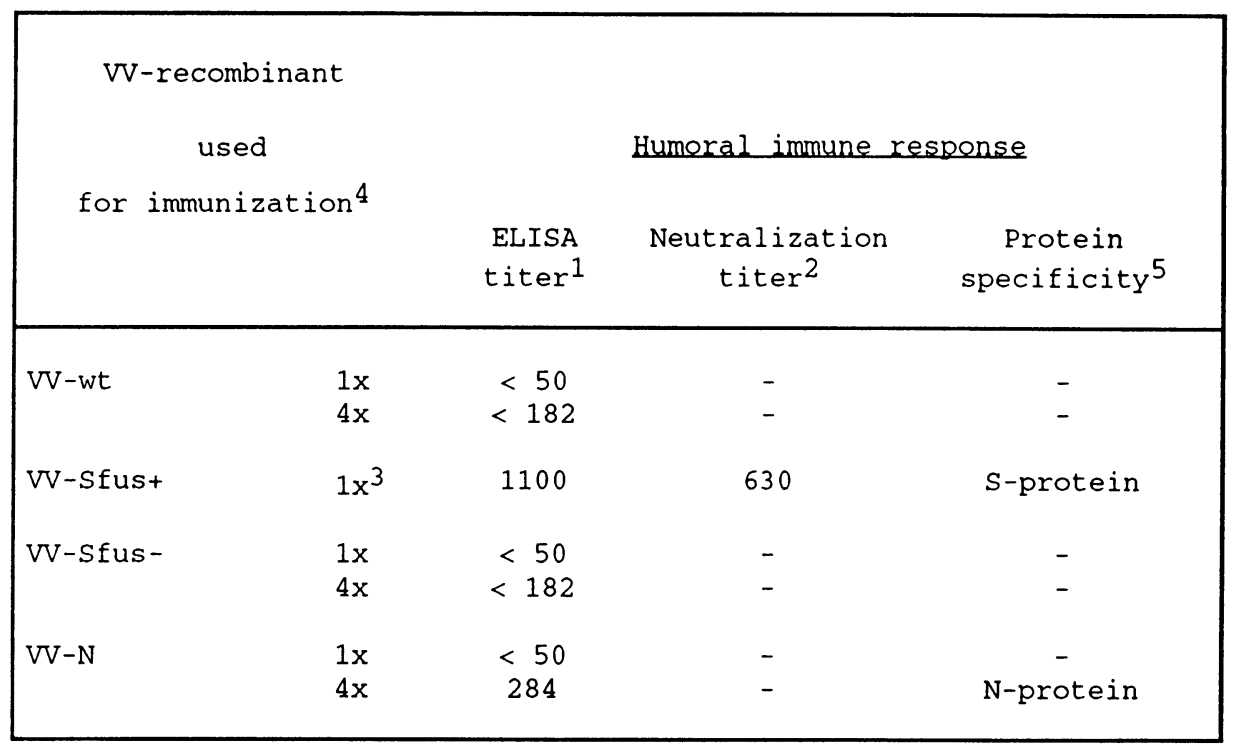

${ }^{1}$ ELISA was performed as described previously ${ }^{4}$. The Units were calculated relative to a graph obtained with a standard antiserum from rats.

${ }^{2}$ Neutralization test was done as described previously ${ }^{4}$. The virus infectivity was measured by plaque assays on DBT cells and the antibody titer resulting in $50 \%$ reduction of plaque $\left(\log _{10} \mathrm{PRD}_{50}\right)$ was calculated.

${ }^{3}$ Pooled serum samples were taken 45 days post immunization

${ }^{4}$ Rats were immunized by i.p. infection with $10^{7}$ p.f.u. of respective VV recombinants. Multiple shot immunizations (4x) were performed at intervals of 5 to 7 days.

5 The specificity of antiviral antibodies was identified by immunostaining of Westernblots. As antigen we used purified MHV-JHM virus, which was separated by PAGE and electroblotted onto nitrocellulose membranes.

antibodies with virus neutralizing activity is present 45 days after immunization. By contrast, the VV recombinant expressing the non fusogenic S-protein does not induce any specific humoral immune response, whether in a single shot or in a multiple shot immunization. Furthermore, the VV-N recombinant elicits a low amount of nucleocapsid-specific antibodies only after four vaccinations. In the plaque reduction assay these antibodies have no neutralizing activity. 


\section{Protective Efficiency of the Immune Response to VV Recombinants}

To evaluate the effect of the MHV-JHM specific immune response on the outcome of infection, adult Lewis rats were vaccinated i.p. with recombinant VV's or VV-wt 7 days prior to i.c. infection with a lethal dose of MHV-JHM (SM3SR2). VV-wt immunized rats and animals vaccinated with either VV-N or VV-Sfus- developed an acute encephalitis and died within 7 to 9 days after challenge (Table 2). In contrast, most animals vaccinated once with VV-Sfust survived the acute phase of disease even when higher MHV-JHM challenge doses were employed. These results demonstrate that the fusogenic VV-S recombinant induces a protective immune response. Furthermore, a VV-recombinant expressing a non fusogenic variant $\mathrm{S}$-protein is unable to mediate protection.

Table 2. Protection of VV-Sfus+ immunized rats from MHV-JHM induced acute encephalomyelitis

\begin{tabular}{|cccc|}
\hline $\begin{array}{c}\text { VV-recombinant } \\
\text { used for } \\
\text { immunization } 1\end{array}$ & $\begin{array}{c}\text { No. of } \\
\text { rats }\end{array}$ & $\begin{array}{c}\text { MHV-JHM } \\
\text { challenge } \\
(\text { LD } 50)\end{array}$ & $\begin{array}{c}\text { No. of dead rats } \\
\text { no. tested }\end{array}$ \\
\hline- & 6 & 5 & $6 / 6$ \\
VV-wt & 14 & 5 & $14 / 14$ \\
VV-N & 18 & 5 & $18 / 18$ \\
VV-Sfus- & 10 & 5 & $10 / 10$ \\
VV-Sfus+ & 26 & 5 & $5 / 26$ \\
VV-Sfust & 14 & 32 & $3 / 14$ \\
\hline
\end{tabular}

${ }^{1}$ Lewis rats ( 3 to 4 weeks old) were immunized once with VV recombinants and were infected with MHV-JHM 7 days later.

\section{Influence of S-specific IgG Antibodies on MHV-JHM Induced Encephalomyelitis}

In order to investigate the influence of virus specific antibodies on MHV-JHM-induced encephalomyelitis, we first studied the time kinetics for the induction of S-protein specific antibodies. We vaccinated rats with the fusogenic VV-S recombinant and sampled serum at different time points. A low concentration of antiviral IgG antibodies was detectable 10 days after immunization (Figure 2). In contrast, 21 days after immunization, high amounts of Sspecific antibodies are present. The first virus neutralizing antibodies were seen 15 days after immunization and a high level of S-specific antibodies with virus neutralizing activity is present 21 days after immunization.

In the following experiments, we performed the challenge of the fusogenic Srecombinant vaccinated rats at two time points; first, at day 7 , in the absence of detectable $S$ specific IgG antibodies, and second, at day 21 , in the presence of S-specific IgG antibodies with virus neutralizing activity. In the absence of antiviral antibodies we observed a strong protection against acute encephalitis. Histological analysis of brain tissue was performed 3 to 6 weeks after MHV-JHM challenge and revealed no pathological changes. In contrast, if the challenge was performed in the presence of S specific antibodies, we observed an interesting modulation of the disease process, namely primary demyelination with characteristics typical of SDE. In the demyelinating lesions MHV-JHM infected cells could be detected. Moreover, the lesions were mainly restricted to the white matter, spinal cord, brain stem and periventricular area. 


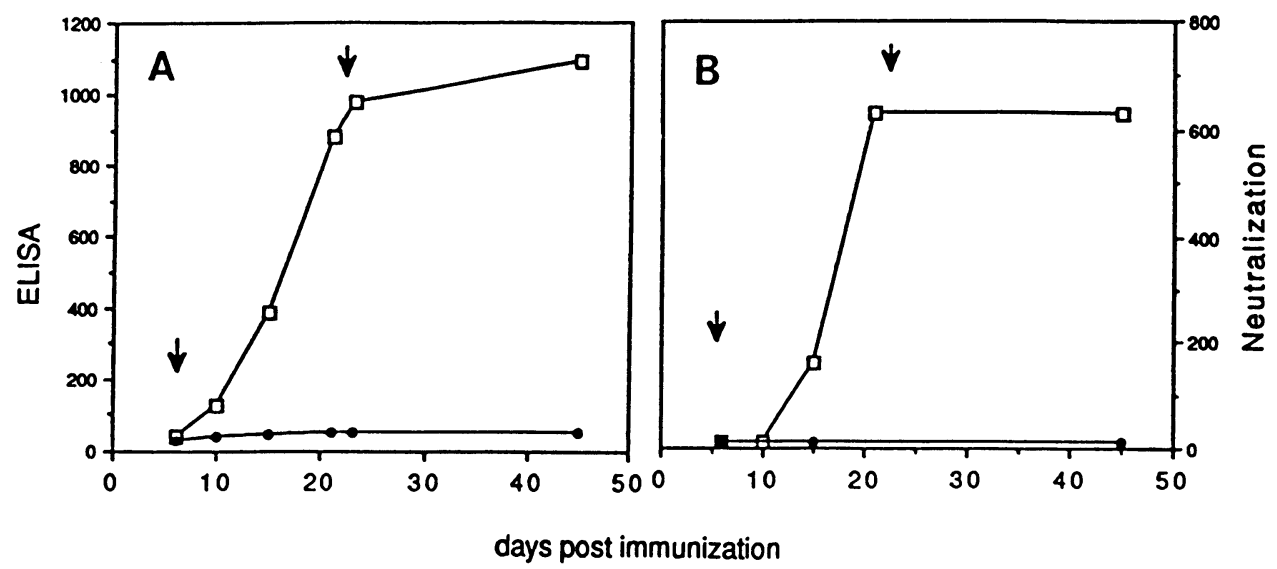

Figure 2. Time kinetics of S-specific IgG antibodies. ELISA test (A) and Neutralization assay (B). The timepoints of MHV-JHM challenge (arrow) in VV-Sfust (open boxes) and VV-wt (closed circle) vaccinated rats are shown.

\section{DISCUSSION}

In a number of virus-host systems, the development of acute diseases can be prevented by immunization against viral surface proteins or internal components $12,13,14$. The outcome of infection varies with the type of humoral and cellular immune responses elicited by different immunization procedures. It is the aim of the present study to analyze the role of the specific immune response to individual MHV-JHM proteins by vaccination with vaccinia virus recombinants.

The S-protein specific humoral immune response is of the major importance to provide protection against reinfection. This is illustrated by results of immunization experiments with Sprotein and specific peptides, which induce neutralizing or fusion inhibiting antibodies 5,6. Furthermore, the transfer of antibodies prior to infection was demonstrated to provide protection. To evaluate the impact of cellular versus humoral immunity, we employed different vaccination protocols with VV-Sfust. Vaccinated rats were challenged at an early timepoint, before antiviral antibodies were demonstrable. The observed rapid clearance of infectious virus indicates that the cellular immune response is of central importance to overcome the acute phase of infection. Another important component is the CD4+ T-cell response. The biological potential of these cells was demonstrated by transfer experiments employing a virus protein specific line of T-cells 10 . The transfer of activated CD4+ T-cells before infection hindered the induction of an otherwise lethal encephalomyelits in Lewis-rats. During the natural course of infection, the classical CD8+ T-cell response (CTL) may also play a role, however a direct functional test is not yet available for the rat system (see Hein et al., this volume). The results from experiments in the mice system indicate that both arms of the T-cell response have to cooperate to eliminate infectious virus from the central nervous system 9 .

In a variety of virus-host systems, the immune response against the nucleocapsid protein seems to be able to mediate protection 15,16 . The role of the $\mathrm{N}$-protein in eliciting a protective immune response during virus infection is not clear. For example, immunization with purified influenza nucleoprotein can induce protection, whereas vaccination with a VVrecombinant induced no protective immunity 17,18 . In our hands, vaccination with the VV-N recombinant could not prevent acute disease regardless of the immunization protocol. However, we could demonstrate a nucleocapsid-specific, humoral and cellular immune response. On the other hand we obtained strong evidence that the $\mathrm{N}$-protein is a very dominant $\mathrm{T}$-cell antigen (see Wege et al., this volume). Therefore, the $\mathrm{N}$-specific $\mathrm{CD} 4+\mathrm{T}$ cell response might have an important helper-function to promote the immune responses of cells and antibodies which lead directly to virus elimination. 
Vaccination with the fusogenic VV-S + recombinant induced a very strong protective immunity. By contrast, we could not protect by vaccination with VV-Sfus-. This non fusogenic $S$-protein variant differs in only one amino acid from the fusogenic S-protein. Since this Sprotein is not processed beyond the gp150-precursor stage intracellularly, we assume that the antigen processing may result in an immune response which is not protective (data not shown).

To evaluate the influence of S-specific antibodies on the course of disease, we challenged VV-Sfus+ vaccinated rats at a time point when a high amount of neutralizing antibodies were measurable. Although these rats were protected against acute disease, a high percentage of rats displayed clinical signs of SDE and histological lesions of inflammatory demyelination. These observation supports our earlier conclusions reached on the basis of immunocytochemical analysis of demyelinating plaques in SDE-rats that in addition to T-cells and macrophages, an antibody mediated cytotoxicity might be one of the factors leading to selective loss of myelin 2 . Suckling mice or rats nursed by immune mothers can develop a subacute disease after infection with MHV-JHM at an otherwise lethal dose 19,20,21. Furthermore, also transfer of antiviral antibodies can delay or modulate the course of neurological diseases 3 . By partial immunization, a modulation of the acute disease to a subacute demyelinating encephalomyelitis can be reproducibly achieved. This observation is an important requirement for further studies on viral and host specific immune responses during the pathogenesis of primary demyelination and relapsing encephalomyelitis.

\section{ACKNOWLEDGEMENTS}

We thank Dr. M. Pfleiderer for providing the VV-Sfus+ and VV-Sfus- recombinants. The work was supported by the Deutsche Forschungsgemeinschaft and Hertie Stiftung.

\section{REFERENCES}

1. H. Wege, S. Siddell, and V. ter Meulen. Curr. Top. Microbiol. Immunol. 99: 165 (1982).

2. F. Zimprich, J. Winter, H. Wege, and H. Lassmann. J. Neuropathol. Appl. Neurobiol. 17: 469 (1991).

3. M.J. Buchmeier, H.A. Lewicki, P.J. Talbot, and R.L. Knobler. Virology. 132: 261 (1984).

4. H. Wege, R. Dörries, and H. Wege. J. Gen. Virol. 65: 1931 (1984).

5. P.J. Talbot, G. Dionne, and M. Lacroix. J. Virol. 62: 3032 (1988).

6. C. Daniel, and P.J. Talbot. Virology 174: 87 (1990).

7. S.A. Stohlman, G. Matsushima, N. Castell, and L. Weiner. J. Immunol. 136: 3052 (1986).

8. M.A. Sussmann, R.A. Shubin, S. Kyuwa, and S.A. Stohlman. J. Virol. 63: 3051 (1989).

9. J.S.P. Williamson, and S.A. Stohlman. J. Virol. 64: 4589 (1990).

10. H. Körner, A. Schliephake, J. Winter, F. Zimprich, H. Lassmann, J. Sedgwick, S. Siddell, and H. Wege. J. Immunol. 147: 2317 (1991).

11. M. Mackett, G.L. Smith, and B. Moss, in: DNA Cloning: A Practical Approach, ed., D. M. Glover, Oxford: IRL Press (1985).

12. M. Hany, S. Schulz, H. Hengartner, M Mackett, M. Bishop, H. Overton, and R. Zinkernagel. Eur. J. Immunol. 19: 417 (1989).

13. L.A. Morrison, S.P. Bauer, J.J. Lange, J.V. Esposito, J.B. McCormick, and D.D. Auperin. Virology 171: 179 (1989).

14. U.G. Brinckmann, B. Bankamp, A. Reich, V. ter Meulen, and U.G. Liebert. J. Gen. Virol. 72: 2491 (1991).

15. J.W. Sumner, M. Fekadu, J.H. Shaddock, J.J. Esposito, and W. Bellini. Virology 183: 703 (1991).

16. W.M. Kast, L. Roux, J. Curren, H.J.J. Blom, A.C. Voordouw, R.H. Meloen, D. Kolakofsky, and C.J. Melief. Proc. Natl. Acad. Sci. 88: 2283 (1991).

17. D.C. Wraith, A.E. Vessey, and B.A. Askonas. J. Gen. Virol. 68: 433 (1987).

18. L. Stitz, C. Schmitz, D. Binder, R. Zinkernagel, E. Paoletti, and H. Becht. J. Gen. Virol. 71: 1169 (1990).

19. S. Perlmann, R. Schelper, E. Bolger, S. Ries. Microbial. Pathogen. 2: 185 (1987).

20. H. Wege, R. Watanabe, M. Koga, and V. ter Meulen, in: Progress in Brain Research, Vol.59, ed., P.O. Behan, V. ter Meulen and F.C. Rose, Elservier Science Publishers B.V. (1983).

21. H. Wege, M. Koga, H. Wege, and V. ter Meulen, in: Biochemistry and Biology of Coronaviruses, ed., V. ter Meulen, S. Siddell, and H. Wege, Plenum Publishing Corporation, New York (1981). 